\title{
Contested Sustainability: Understanding the Inertia of Sustainable Development Paradigm
}

\author{
Imoh Imoh-Ita \\ Department of Public Administration, Akwa Ibom State University, Uyo \\ Obio Akpa Campus.
}

\begin{abstract}
Since its postulation in 1987, Sustainability has attracted increasing scholarly and policy attention and perhaps oneof the most valuable assets in the overall development paradigm. It is also a contestable term in practical contexts. This articleis a relational content analysis(RCA)which exploreslaudatory and pejorative perspectives associated with the sustainable development discourse. Using the Marxist Political Ecology Framework attention is drawn to recent global trends and changes which constitute challenges to the sustainable development agenda notably; global poverty and inequality, terrorism and insecurity, Western consumption patterns, urbanization and environmental degradation, globalization, Western lifestyle and resource efficiency,etc. Primary data was collected through self-administered survey of 20 environmental based NGOs in five high income countries conducted between May 2011 and January 2013. While secondary data derive from books, bulletins, reports, internet materials etc.The research findings suggestthat the high income countries have poorly internalized the ideals of sustainable development. The paper made some policy recommendations.
\end{abstract}

Keywords: Ecological Justice, Greening, Unsustainable Consumption, Inequality, Sustainable development.

\section{INTRODUCTION}

In 1987 the former Norwegian Prime Minister Gro Halem Brundtland was commissioned to provide a blue print on sustainable development which resulted in the seminal Brundtland commission report. Sustainable development has three key components namely; environmental, social and economic which are integral to the understanding of the overall sustainable development paradigm.

As Sustainable Development Goals(SDGs) takes toll as a post 2015development agenda, a number of factors such as Means of Implementation(MOI),global terrorism and insecurity, consumption patterns of the affluent societies, deleterious environmental exploitation, persistent natural disasters, and the non- ratification of the Kyoto Protocol with its two commitment periods, from2005-2012, and the other between 2012- 2020by the United States, provide contradictory images of the commitment of the affluent societies to sustainable Development.

Beyond these, over the four decades, implicit challenges to sustainable development are discernible such as deleterious environmental consumption including environmental pollution, global dichotomy replicated in division of the world along rich(North)and Poor(South) lines, the dynamic realities of demographic changes, globalization and technological advancements etc.

Against the backdrop of ecological concerns are recent studies which examine the impact of resurgent Western lifestyle on sustainable human development(SHD) such as man sex man(MSM) and woman sex woman (WSW) resulting in the same sex marriage legalization debate (Amadi and Wordu,2016).

There is increasing need to understand the implications of these trends in studying sustainable development. Such arguments are significant as they are largely linked to the challenges constricting sustainable development in line with several others notably the persistent environmental insecurity arising from deleterious resource use and more recently the evidence of global insecurity across Europe, America, Asia, Latin America and Africa. The increasing distortions of the earth, reassert the need for critical engagement in the sustainability paradigm.

Similarly, the 2012 Rio+20 summit outlined a number of challenges such as, food security, decent jobs, energy, oceans and disaster readiness ,sustainable cities ,sustainable agriculture, water 
(Rio,2012). In 1992 the World Summit on Sustainable development (WSSD) at Rio de Janerio gave greater impetus to sustainable development with Agenda 21 the blue print for implementing sustainable development.

At the turn of the millennium, the United Nations Millennium Declaration was adopted by world leaders in September 2000 which gave impetus to the Millennium Development Goals (MDGs)-a framework for development yardstick with 8 goals and 18 targets. Both laudatory and opposing perspectives on the Millennium Development Goals (MDGs) and its development proclivities abound (see Easterly, 2009; Sachs, 2015).To strengthen the sustainable development paradigm resulted in the adoption of Sustainable Development Goals (SDGs).

Recent environmental challenges suggest that researchers, students, international development experts, and similar stakeholders have become increasingly concerned with the resurgent impasse in development theory (Hove, 2004; Schuurmann, 2014; Amadi, et al; 2016).Perhaps this impasse reemerges as a perennial development problem that points to more critical evaluation of the sustainable development debate.

Schuurmann (2014:21) identified three key reasons responsible for the impasse (a) the failure of development in the South and the growing diversity of (underdevelopment experiences;(b) the postmodernist critique on the social sciences in general and on the normative characteristics of development studies in particular and finally(c) the rise of globalization in its discursive as well as its ontological appearance.

Persistent poverty and inequality that faced the periphery increasingly confirmed the inability of the modernization paradigm to foster economic advancement. This is largely due to the decline of the modernization theory to provide development transformation among the less developed societies of the global South since the 1980s as inequality and poverty remained pervasive (Pieterse, 2010).It becomes increasingly difficult to measure the level of inequality among the rich and poor societies.

The dominant theories of development in the late 1980s began to look at a more encompassing and comprehensive framework beyond the economic framework. Sustainable development since 1987 reflects the social, economic and environmental parameters of the present and future generations.

The recent adoption of Sustainable Development Goals (SDGs) elicits greater scholarly attention as the attainment of sustainable development has perhaps remained an elusive endeavor at a time ofreevaluating a number of issues such as Western consumption and production patterns as well as life styles.

The guarantee for this development premise has been complex and contradictory in the present global realities of deleterious environmental and natural resource use. Thus, the sustainable development paradigm has never been without critiques. Merle Jacob (1994) provides a methodological critiqueof sustainable development to examine key flaws of the development paradigm. Most recent debates contend that possible crisis are replete in the sustainable development agenda (Korten,1995;Amadi,et al;2015).Such contention according to David Korten (1995) is a fundamental attribute of development crisis emerging from the clash of ideological, economic, social, cultural, political, and technological forces in the era of western globalization. Korten (1995) identified a development shift from responsible government to government by a handful corporate organizations and financial institutions informed by the logic of globalization. The politicization of sustainable development becomes discernible as post global environmental summits have minimally impacted global response to environmental transformation (Scuftan, 2003).

The article explicates consequences of the failure of this robust paradigm to sustainably deliver ecological justice and equality. Beyond this, transform environmental resource use by the countries of affluent global North. Korten (1995) identifies a number of myths that surround the global economy and these have been the offshoot of a broader debate that starts as a discussion on the changing realities of environment with effects such as green -house emission, ozone depletion, climate change, volcanic eruption, hurricanes, cyclones, earth quakes, tsunamis etc. The current debate on sustainable development has the potential to trigger a paradigm shift, not only among stakeholders in development studies and wider social discourse, but in global ecological policy discourse.

The article explores the theoretical re-evaluation of the sustainable development agenda and strategic strengthening of the prevailing paradigm. It explores the political character in the overall debate on sustainable development in order to identify gaps in development studies that are considered necessary. 
Depoliticized sustainable development against a tradition of politicized social system is actually a more prospective strand to propagate the sustainability paradigm, and to question the dominant roles of the affluent societies, including the role of legal and political institutions and all key stakeholders in the sustainability discourse.

The article will attempt to address gaps in sustainable development theory and criticism. This gap is the dearth of analysis of contemporary Western lifestyle and consumption patterns and the increasing effects on the environment and wider human society.

The article examines both the commemorative and pejorative strands of sustainable development and moves beyond the paradigm of principles to the paradigm of implementation. The aim is to rearticulate the rhetoric and fluidity of the sustainability debate. The subsequent section examines the methodology deployed for the research.

\section{Materials AND Methods}

Inequality in the consumption of natural environment has taken a novel turn in the neo liberal order. The Marxist political ecology examines the complexities of this unequal relationship in exploiting natural resources and underscores the relevance of sustainable and equitable resource extraction.

Sustainability is critical in appraising the dynamics of ecological justice and equality in harnessing nature. In advancing the "contested sustainability" debate, the contradictions of the global power structure and inequality in access to the use of natural resources finds plausible expression within the Marxist political ecology perspective.

Thus, ecological Marxism has deployed divergent approaches to the study of ecological issues affecting human environment. This underscores the suitability of the political ecology framework (Burkett \& Foster, 2004; Gareau, 2004). The political ecology framework perhaps provides broader understanding of the logic of the interaction between humans and their response to the exploitation or preservation of natural resources.

For the methods of data collection, primary data on environmental consumption was deployed with online survey conducted between May 2011 and January 2013. The study builds on Stern, (1997) which provides seminal insights on consumption as a problem confronting environmental sustainability. Virtual online questionnaire guide with semi -structured questions were administered to respondents based on a sample size of 750 respondents in the twenty randomly selected development and environmental based Non- Governmental Organizations (NGOs) in Europe and America.

The instrument of primary data collection was a semi- structured questionnaire titled; Sustainable development and Western consumption pattern and lifestyle (SUDWECPAL). Percentages, weighted mean and standard deviation were used to answer the research questions.

A review of relevant secondary data was also conducted using a relational content analysis (RCA) which further provides in-depth analysis on patterns of ongoing asymmetrical environmental resource consumption involving the high income societies and the effects on the environment and the wider human society. The aim is to review relevant secondary data and identify research gaps and future policy direction. The research covers the periods 1990 to 2014 which is important to understand and asses post 1992 World summit on environment, Sustainable Development Goals (SDGs) a post 2015 development agenda and commitments to environmental sustainability by the industrialized societies.

\section{DEVELOPMENT AND SUSTAINABILITY}

In the late 1980s sustainable development gained visibility in international development discourse(WCED,1987;UNCED,1992;WSSD,2002).Sustainable development is defined as the development that meets the needs of the present generation without compromising the ability of the future from meeting theirs (WCED,1987). It has three key components namely; the environmental, social and economic. The sustainable development debate has gone beyond this to provide a more robust paradigm at the post Rio Summit in 1992 following Agenda 21.Divergent perspectives and debates have deployed the term sustainability to describe a number of studies and scholarly conceptualizations including, greening, ecology, triple bottom line, de-materialism, consumption patterns, lifestyles, environment, human development and more recently sexuality (Amadi, 2014). Thus, diverse concepts are now associated with the sustainable development paradigm. 
Against the background of divergent perspectives on sustainable development, the interrogation of development within the sustainability context seem to have attracted les scholarly attention (Davidson and Hatt, etal, 2005).Sustained treatments and critical engagements that theorize sustainable development as contentious in practical terms and critically reposition sustainability at the centre of development studies both as a policy issue and mode of inquiry have been scant (Amadi, et al;2015).

Within its three dimensions of economic, social and environmental, closer observation reveals that sustainable development has been uncritical in institutionalizing its core tenets(Jacob,1994).For instance, the 2008 global economic recession emerged with economic, social and environmental distortions of great consequences. Much of this is reflective of the evidence of neoliberal trajectories in undermining equitable resource extraction (Harvey, 2005).

Considerably, this concern has been increasingly relevant in substantiating how sustainable recent development enterprise has been faring. This contention reflects the dearth of studies specifically interrogating sustainable development and in particular, studies directly examining sustainable development theory and practice.

Essentially, there are a number of local and international conferences bearing the theme sustainable development; there are equally various studies in the literature on a number of aspects of sustainable development since the late 1980s. Never the less, deepened studies on sustainability at local and global conferences and conventions are suggestive of the need for novel re- engagement and exploration of sustainability paradigm.

As a commonly used term, sustainability has had a wide scholarly and research reach among affluent and poor societies and has also become a sort of framework for capacity development and similar workshops by multi- lateral organizations in a wide areas of study notably the environment, the economy, socio- cultural endeavors, politics, geography etc. This often invokes the re-evaluation of the concept beyond mere descriptive analysis. And towards meeting the core development needs of the poor and marginalized segments of the society. Thus, institutionalization of policy frameworks on efficient resource use and sanctions to defaulters seem elusive. For instance, the COP and US non ratification, the test of Atomic bomb by Iran in 2014 have not been internationally punished. Such mere descriptive use of sustainable development creates some critical flaws both in policy, development and analytical strands and in particular among the affluent societies.

The increasing controversy within the sustainability debate is emblematic of the complexities of the concept and elusive development challenges such as vulnerability of climate change. This underscores the persistent contention from pro and anti- development perspectives pointing out that Western development project has failed (Sachs, 1992; Escober, 1995).

Developmentally, whereas a descriptive approach sees sustainable development in theoretical terms as a clear product of rhetoric, aimed at communicating to the wider population how humanity ought to interact with one another and the environment. How the poor societies have been transformed from a condition of lack to wellbeing in the era of sustainable development is largely unknown, poverty and inequality remains high (Weinstein, 2008).

The operational institutional approach seeks clearer understanding of the functioning of the sustainability project as a practice integral to institutional survival. It marks the need for evidence based recognition of the realities of sustainability in concrete terms involving all stakeholders and in particular in relation to the wider natural environment including human and non- human species. This underscores a complex and multi-faceted dynamic and the central thesis of this paper.

The superficial grasp of existential realities of the poor societies, the marginalized and disadvantaged notably women and the girl child, reveal the growing concern surrounding sustainable development. This has a hugely significant effect and vitiates the sustainability agenda as more of a descriptive exercise implicitly linked with capitalist natural resource exploitation (Harvey, 1995).

Politically, sustainability theory should increasingly consider the response of key actors and stakeholders towards strict compliance to sustainability policy frameworks such as global negotiations. As a development that is pro poor, pro nature and pro women, sustainable development should have a multi-dimensional response to the entire problems of environment and humanity in general, also backed with multicultural policies and similar responses. 
References to variations in life style and consumption patterns as contrary to dominant ethos of sustainability have appeared in writings critical of sustainability debates (Davidson \& Hatt; et al;2005). An assessment of the sustainable development construct is import to understand the theoretical trends involved in its politicization-although few scholarship would contest that there is a symmetrical development between the industrialized North and poor South.

In development studies, a number of recent debates point to novel examination of sustainable development, several factors are identified such as the struggle for global hegemony and market economy in the neo liberal order. This left the sustainable development studies and policy framings at a superficial level.

Nederveen Pieterse, (2012) argues that recent studies have emerged to critique Western development projects and its associated failures within, economic, institutional, ideological and cultural hegemonies. Much of these centers on Western lifestyles and consumption patterns have attracted scholarly attention (Hawken, etal; 1999; Hobson, 2003; Davidson and Hatt, et al; 2005).

Another paradox is that sustainability's unclear boundary results in development unpredictability. Issues such as equity, well-being etc (Dasgupta, 1993), are often less prioritized. Holdren, et al ; 1995) contend that equity is worth examining in sustainable development as they are biophysically (as well as socially) unsustainable.

Proclaiming sustainability as the dominant characteristic of contemporary culture, Davidson and Hatt, et al ; (2005) explore the contemporary consumer culture- which provides the conceptual limitations of sustainable development discourse as consumption is now conceived as a Western hegemony. Paul C Stern (1997) argues that consumption has been a key challenge to sustainable development.

These contradictions have become avenues through which critics repeatedly attack sustainable development as poorly conceptualized to impact the poor societies. This forms the theoretical basis of debates among scholars on novel sustainability agenda.

Much of this is amply explored from the lens of scholars that argue about the plausibility- and /or realistic implications- of sustainable development (Schuftan, 2003). Davidson and Hatt, etal; (2005) demonstrate this concern when they argue that sustainable development is increasingly affected by resurgent Western hegemonic powers involving global corporations.

Sustainability is meaningless as a description of - development, if it merely interprets development as an abstract entity. Sustainable development as an abstract and analytic concept is always contradictory. For instance some critiques argue on how to evolve common standards to measure sustainability (Kovel, 2000; Lamberton, 2005;Amadi, et al; 2016).

Another critique of sustainable development is that it is a form of self-indulgence by Western environmentalists. This argument is reinforced by scholars who argue that sustainable development has shown less commitment to developmentalism such as eco- feminism, eco- city, greening etc( Harvey,2005; Amadi et al;2015).Globalization for instance has provided complexities that contradict sustainable development (Rosenau,1996; Chomsky, 2002;Bello,2003).

Neoliberal doctrine and proponents of globalization argue that unrestrained trade and reduction of public-sector regulation will be beneficial to poor societies and the disadvantaged even in rich countries(Tomlinson,2003). While the anti-globalization debates argue that globalization fosters inequality which is anti- developmental(Rosenau,1996;Chomsky, 2002;Bello,2003).For instance, Bakari, Mohamed El-Kamel (2013 )contends that globalization and sustainable development are false twins. This suggests their incompatibility in development contexts.

Noam Chomsky (2002) states that the term"globalization"has been appropriated by the powerful to refer to a specific form of international economic integration, based on Western interest. Michel Chossudovsky (2015) buttresses the imminent dangers of globalization of poverty. The challenges of market fundamentalism and increasing contradictions of capitalism is echoed in debates which see contradictions between capitalism and sustainable development as capitalism is riddled with exploitation and profit maximization(Harvey,1995).

For instance, Soros (2008) contends that the so-called Washington consensus imposed strict market discipline on other countries, but the US was exempt from it. This reinforces the growing debates on Western imperialism. This debate is explicated within the nature capitalism school a strand of the imperialism debate (Hawken,et al;1999). 
David Harvey (1995) provides novel insights on new imperialism and demonstrates the exploitation of nature, much of this debates is reinforced in Collier (2010) and the re-evaluation of the "plundered planet". Similarly, Alex Calinicos (2009) demonstrates resurgent economic asymmetry and systemic inequality arising from imperialism. In her views, Vanda Shiva (2002) provides explication of wars on Nature. Related account is elaborated in recent works on ecological breakdown ( Amadi et al;2016).

Davidson and Hatt, etal; (2005) argue that sustainability among the affluent societies is a political dead-end with minimal commitment. In ethics of sustainability scholarship, this argument is taken up against post- developmental theory (Gasper, 2012; Kibert, et al; 2012).Wolfang Sachs (1992) contends that contemporary development "is what it is not". Another argument against sustainability is the increasing challenges of ecological justice which remains at issue among critics and proponents of politicization of sustainability. The use of sustainability has thus been criticized as politically suspicious because it allegedly lends legitimacy to a corporate rhetoric that results deleterious resource use (Korten, 1995). William Easterly (2005) provides one of the central critical reappraisals of sustainable development arguing especially among the poor societies.

A similar account is replete in the politicization of sustainability debate including the discussions of the meanings and implications of multiculturalism. Here, sustainability is seen as a strategy of cooptation used by the corporate power holders to appropriate environmental resource (Korten1995; Bakan, 2005).

The cultural globalization debate demonstrates culture mutation- as an attribute of globalization and asymmetrical interaction with periphery cultures (Amadi, etal; 2016).Thus, cultural sustainability is perhaps threatened as issues of creolization, uniculturality, genetically modified (GM) crops etc are at variance with sustainable development.

The understanding and implementation of sustainable development in an asymmetrical international capitalist system, varying economic progress, inequality, consumption patterns and reception to nature and ethical values invite novel critical engagement. To that end, this article revisits sustainable development in the context of contested notions which point to the politicization of sustainable development paradigm by the affluent West.

A number of scholars demonstrate concerns about post developmentalism and development failures (Sachs, 1992; Escober, 1995). The post Washington Consensus, the architecture of market fundamentalism provides a number of features which are at variance with sustainable development, driven by economic and market principles. Profit maximization not sustainability has been the motive force and translates to marketization of nature or what Paul Hawken, et al., (1999) termed nature capitalism.

The postulation of several new targets for development, notably the Millennium Development Goals, ( MDGs) helps to divert attention from the fact that no previous targets have been even remotely attained (Nederveen Pieterse,2010). This provides ever more increasing pressure and critical look at the sustainable development goals (SDGs) as a post 2015 development agenda.

Development thus remains, "a rhetorical industry, an ideological performance premised on capitalist production and paradigm maintenance"(Nederveen Pieterse, 2010). The ideological proclivities of neo liberal development project invoke a number of critical re- evaluations of sustainable development such as capitalism and inequality, globalization and deleterious natural resource consumption.

Thus, there have been challenges of persistent global asymmetry characteristic of the prevailing international system. The clamor for good governance and transparency are ways of sharing the Washington utopia. As states retreated from society, NGOs filled the space (Nederveen Pieterse, 2010). Novel questions and trends that confront sustainable development seem unattained such as same sex marriage and the future of humanity in the context of procreation, poverty, unemployment and empowerment of the poor, terrorism, and women's vulnerability, the disease economy of the periphery societies notably HIV/AIDS and Ebola virus(EBV). The increasing challenges of climate change vulnerability, ecological breakdown, ozone layer depletion, racial discrimination, gender inequality, rural/ urban dichotomy, global North /South dichotomy are critical sustainable development questions.

A step beyond the usual concerns of neo liberal criticism is plausible to understand the realities of the enormous challenges of Western poor proclivity to sustainable development. Although there is some 
evidence on green movement across Europe and America, critical re-assessment of the discourse of prevailing sustainable development is found in debates among scholars who argue that corporate giants and multinationals are key challenges to sustainable development (Korten, 1995; Harvey, 2005; Davidson and Hatt, etal, 2005).

The insights offered by critics of sustainable development underscore the ambiguous and disputed meanings of the concept. However, they merely describe sustainability's controversial status, and stop short of engaging it as problematic. After all, if sustainability is pervasive, as most scholars of development (Sachs, 2015) seem to agree, then we do need to re-engage in its critique or develop contextual tools to tackle its ambiguity.

Significantly, sustainability is largely critiqued as prescriptive as its mode of implementation has been weak and rarely binding on nations who violate the rules of the game especially the affluent societies. For instance, the United States and the non- ratification of the Kyoto Protocol provides contradictory images of her commitment to sustainable development.

The subsequent section examines dimensions of contradictions of the sustainability paradigm as follows;

\subsection{Urbanization and Environmental Degradation}

In the current global system rapid urbanization is discernible (Hinrichsen,et al;2002; Baker,2005). According to a recent report, urban areas are gaining an estimated 67 million people per year-about 1.3 million every week (UN, 2002; Hinrichsen, et al; 2002). By 2030 about 5 billion people are expected to live in urban areas - 60\% of the projected global population of 8.3 billion (Hinrichsen, etal; 2002). A key challenge to urbanization is the destruction of the natural habitats and ecosystem. Achieving eco cities have been at issue(Caprotti,2014).Similar challenges such as the green city(UNEP,2011), have been enormous as rapid urbanization negatively impacts environmental sustainability(Lye Liang ,2010).

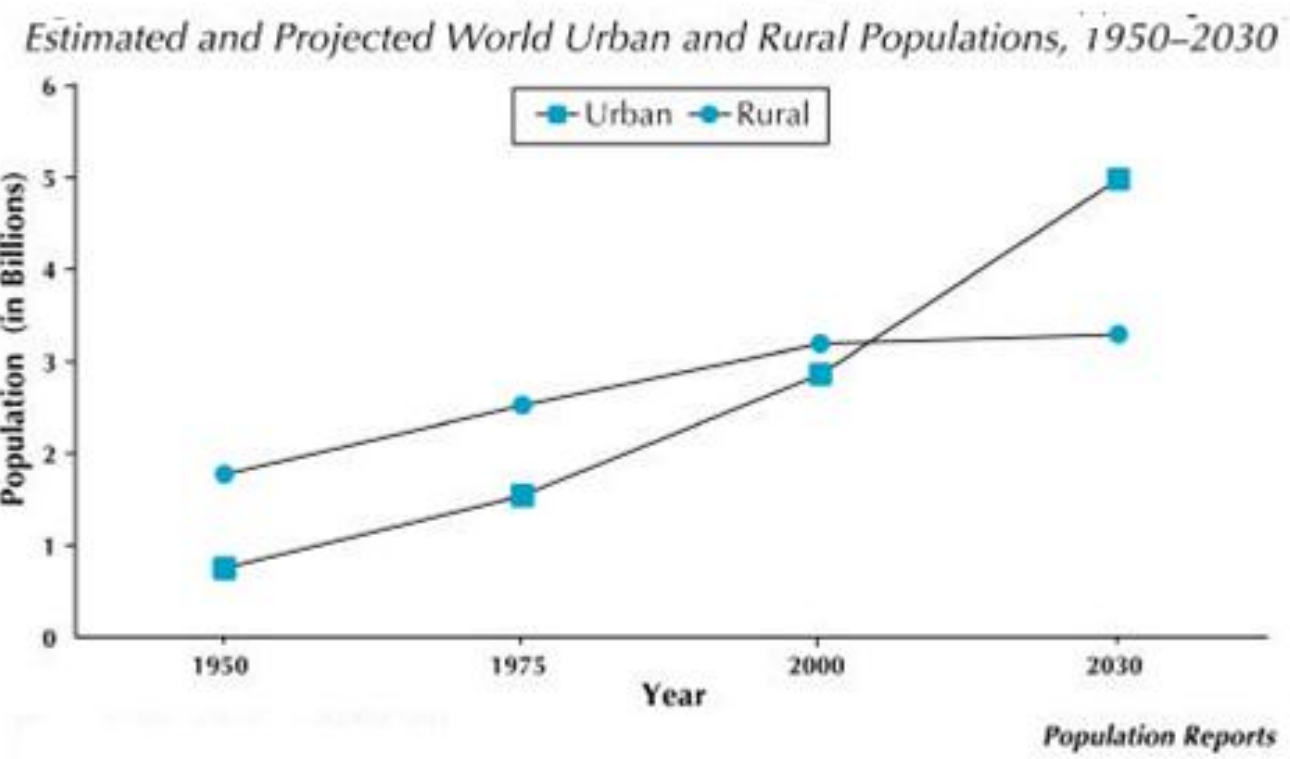

Figure1.World's Urban Population Growing Rapidly

Source: United Nations, 2002

\subsection{Global Poverty and Inequality}

Global Poverty and inequality index remains ever higher today than hundred years ago (Birdsal, 2005; Weinstein, 2008; World Economic and Social Survey 2013).The sustainable development paradigm has not alleviated the massive poverty in the low income countries (World Bank, 2015; Amadi and Igwe, 2015). Sub-Saharan Africa ranks high on global poverty levels, reaching over $50 \%$ of the urban populations in Chad, Niger, and Sierra Leone (Hinrichsen,et al;2002). Sustainable development does not thrive amidst poverty and inequality. The issues of inequality remain a global concern. Over one billion people are confronted with the incidence of poverty, similarly income inequality remains wide both at the individual and country levels (World Economic and Social Survey, 2013). 
Collier (2010) argues that unsustainable consumption and production patterns pose hugely significant challenges to human and environmental existence including effects on economic and social costs and in particular endanger human and animal species on the planet. The World Economic and Social Survey, (2013) reports that world reached the poverty target five years ahead of the 2015 deadline. The data shows that the periphery societies harbors a large number of persons who subsist on less than a 41.25 a day which stood at $47 \%$ in 1990 to $22 \%$ in 2010 .The report shows that about 700 million fewer people lived in conditions of extreme poverty in 2010 compared with 1990. That despite this, results fall short of international expectations and of the global targets set to be reached by the 2015 deadline (World Economic and Social Survey, 2013).

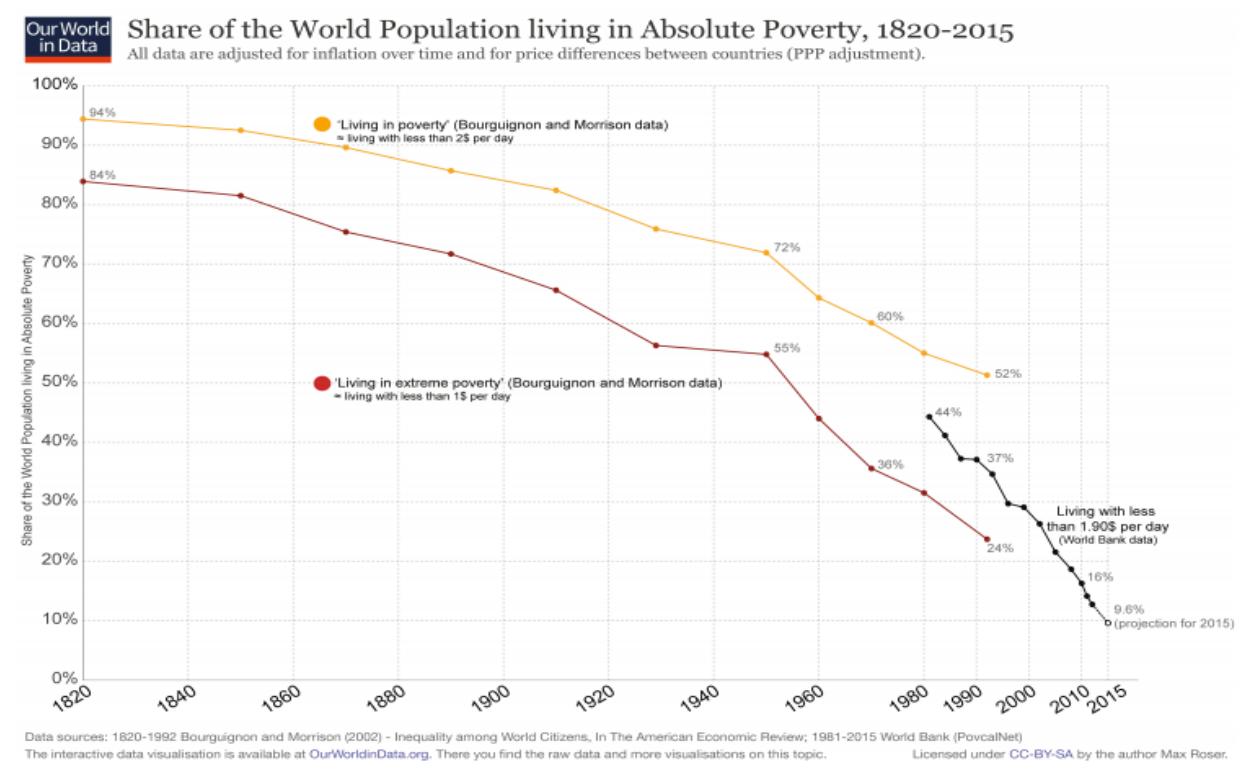

Fig2.Share of the World Population Living in Absolute Poverty 1820-2015

\subsection{Terrorism and Global Insecurity}

The post 9/11 attack and recent terrorist attacks both in the developed and developing societies point to the urgency of rearticulating the sustainable development paradigm. In the global South the Middle East has been at the centre of terrorist attacks with several global terrorist groups such as al-Qaeda, alShabaab, ISIS, Boko Haram in northeast Nigeria etc. Global Terrorism Index (GTI) has been an insight on ranking of terrorist incidence among nations. Popularized by the Institute for Economics and Peace (IEP).The index illustrates trends associated with terrorism in a ten year period. The data for the index derives from Global terrorism database (GTD) codified with case examples of terrorism (Institute for Economics \& Peace,2015).The data base is a research outcome of the national Consortium for the Study of Terrorism and Responses to terrorism (START)based at the University of Maryland United States. The recent data suggests that global terrorism has been on the increase. This $\mathrm{v}$ poses greater security threat to humanity.

\subsection{Western Consumption Patterns}

Juliet Schor, (2005) argues that the 1990s and early 2000s have been a period of rapid consumption growth for the average household, as consumption outpaced income growth, and savings rates declined.

Several influential critical works have inspired the understanding of Western consumption culture and lifestyle. Schor (2005) showed that Between 1993 and 2004, real personal consumption expenditures per capita rose from $\$ 19,593$ to $\$ 25,973$ (2000 dollars), or 33\% Terpstra and David (1991) contend that this consumption culture is an attitude that was learned overtime including a set of orientations for the people which over time becomes a way of life. Hofstede (1980) provides four dimensions of culture: strong versus weak uncertainty avoidance, individualism versus collectivism, large versus small power distance, and masculinity versus femininity.

Western culture and sustainable development nexus remains critical in development studies. Schor, (2005) explored the consumption patterns of US households and environmental degradation and showed that a central cause of that degradation is the growth of US private consumption 
(Wackernagel, 1999; Wernick, 1997; Schor,2005).Similarly, in Canada, Davidson and Hatt,et al; (2005)show the increasing negative effects of corporate resource consumption by large multinationals. According to figures presented by William Rees of the University of British Columbia at the annual meeting of the Ecological Society of America, human society is in a "global overshoot", consuming $30 \%$ more material than is sustainable from the world's resources.

A recent data by World watch Institute (2011) shows the increasing disproportionate challenges of Western consumption on the environments. The number of urban residents without access to improved water sources rose from 113 million in 1990 (5\% of the total urban population) to 173 million in 2000 ( $6 \%$ of the total urban population), according to a study by WHO and UNICEF (2002). Harvey (2005) argues that neoliberalism and its component features are primary triggers of environmental degradation as the influence and dominance of capitalism emerges as a global phenomenon; it is the elevation of capitalism, as a mode of production that results in the logic of un sustainability as capitalist accumulation takes divergent exploitative dimensions

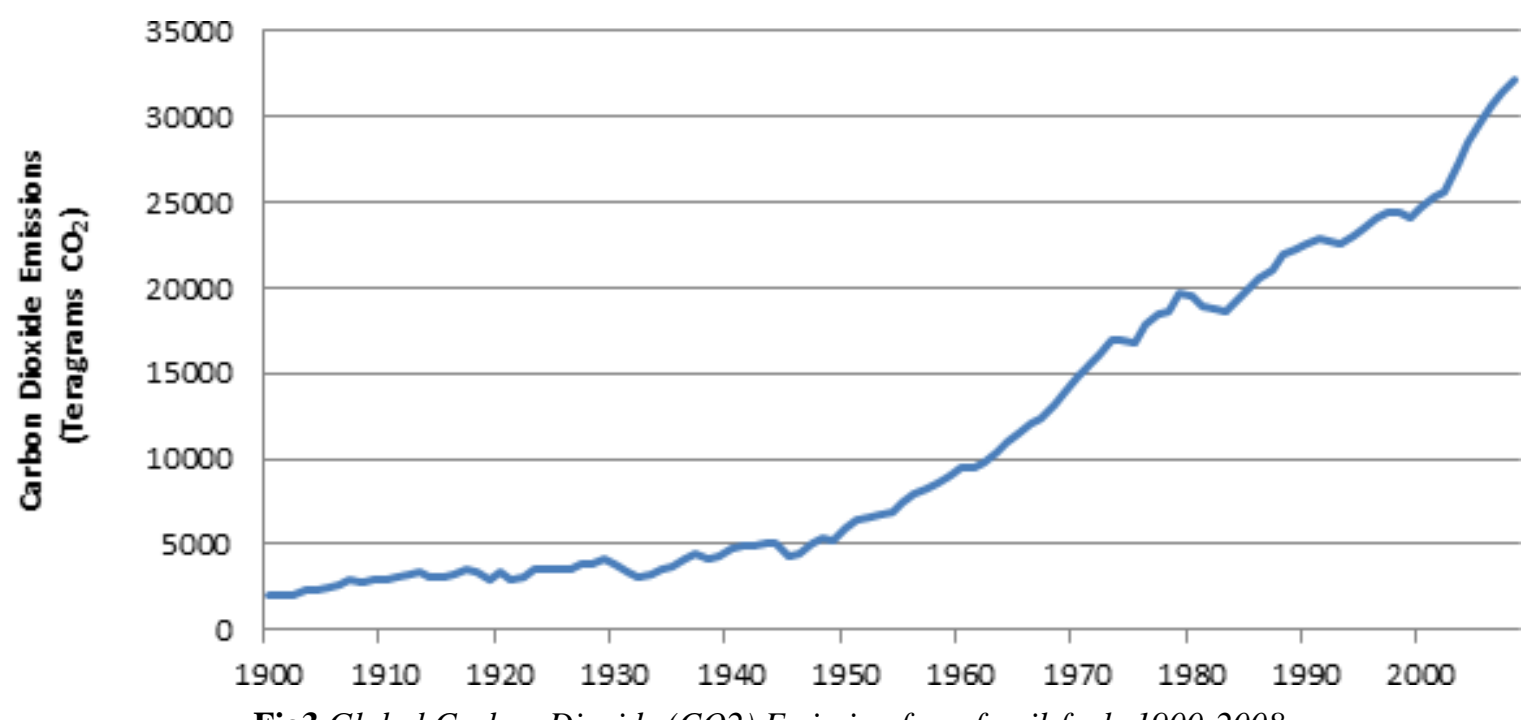

Fig3.Global Carbon Dioxide (CO2) Emission from fossil-fuels 1900-2008

Source: Boden, T.A., G. Marland, and R.J. Andres (2010). Global, Regional, and National Fossil-Fuel CO2 Emissions. Carbon Dioxide Information Analysis Center, Oak Ridge National Laboratory, U.S. Department of Energy, Oak Ridge, Tenn., U.S.A. doi 10.3334/CDIAC/00001_V2010

\subsection{Globalization}

Globalization has been explored from a number of perspectives, particularly; it has resulted in novel economic and technological trends such as bridging information gaps. In development literature its effects such as inequality have been foreshadowed (Weinstein,2008;Pieterse,2010). Within environmental contexts, Korten (1995) notes that although economic output has experienced a fivefold increase since 1950, the ecosystem cannot sustain its present growth. He believes that it is more than a failure of government bureaucracies. The process of economic globalization is shifting power away from governments responsible for the public good and toward a handful of corporations and financial institutions driven by a single imperative - the quest for short-term financial gain.

One popular argument against globalization is the protection of natural resources. This is part of a common non-economic argument against foreign direct investment "to protect national security." Based on a fear that critical resources like food and petroleum will be in scarce supply in times of political unrest, governments often protect these resources with trade barriers and subsidies. Ohmae (1995) calls this the "resource illusion" and says that in fact, countries are actually slowing their own growth. He goes on to say that growth depends on leveraging value-adding economic linkages that ignore political borders.

The cosmetic internationalization of sustainability is further demonstrated with genetically mutilated crops, creolization, which has health implications such as cancer. Based on a "customer-as-king" cliché arguing in favor of the alleged benefits of transnational capitalism to the world population, sustainability is enlisted as a natural dimension of global strategic marketing, predicated on 
conquering diverse niche markets. Thus transnational capitalism is painted as a progressive force spearheading the global expansion of democracy (Harvey, 2005).

This corporate discourse evokes the interrelated themes of customer desire and satisfaction, the retreat or weakness of the state, and the conflation of capitalism with democracy. These are the principal tenets of economic neoliberalism, a philosophy of governance that has been ascendant for several decades and has become the dominant policy mode in leading political and economic circles. This vision of sustainable development is thus grounded in the neo-liberal ideology driving the current stage of globalization, with its relentless push towards opening new markets, dismantling state barriers to market expansion, and widespread consumerism. Sustainability is thus professed as an important element of transnational corporate multiculturalism.

\subsection{Western Lifestyle and Resource Efficiency}

Some patterns of Western lifestyle is argued to be largely at variance with sustainable development (Hobson, 2003; Schor, 2005; Davidson and Hatt, etal; 2005).In the 2000s several European governments legalized same sex marriage. In 2015 the American government followed suit. This has further triggered novel homophobic attacks in Europe and the United States. Such lifestyles perhaps are counter to sustainable human development defined by OECD (2006) as development that is pro human, pro nature and pro poor in the context of procreation. The central long term challenge it poses to child rearing is less theorized.

In 1992, at the very first United Nations Conference on Environment and Development (UNCED), former United States President, George H.W. Bush, declared that; "The American way of life is not negotiable"( Pierre-Louis,2012).

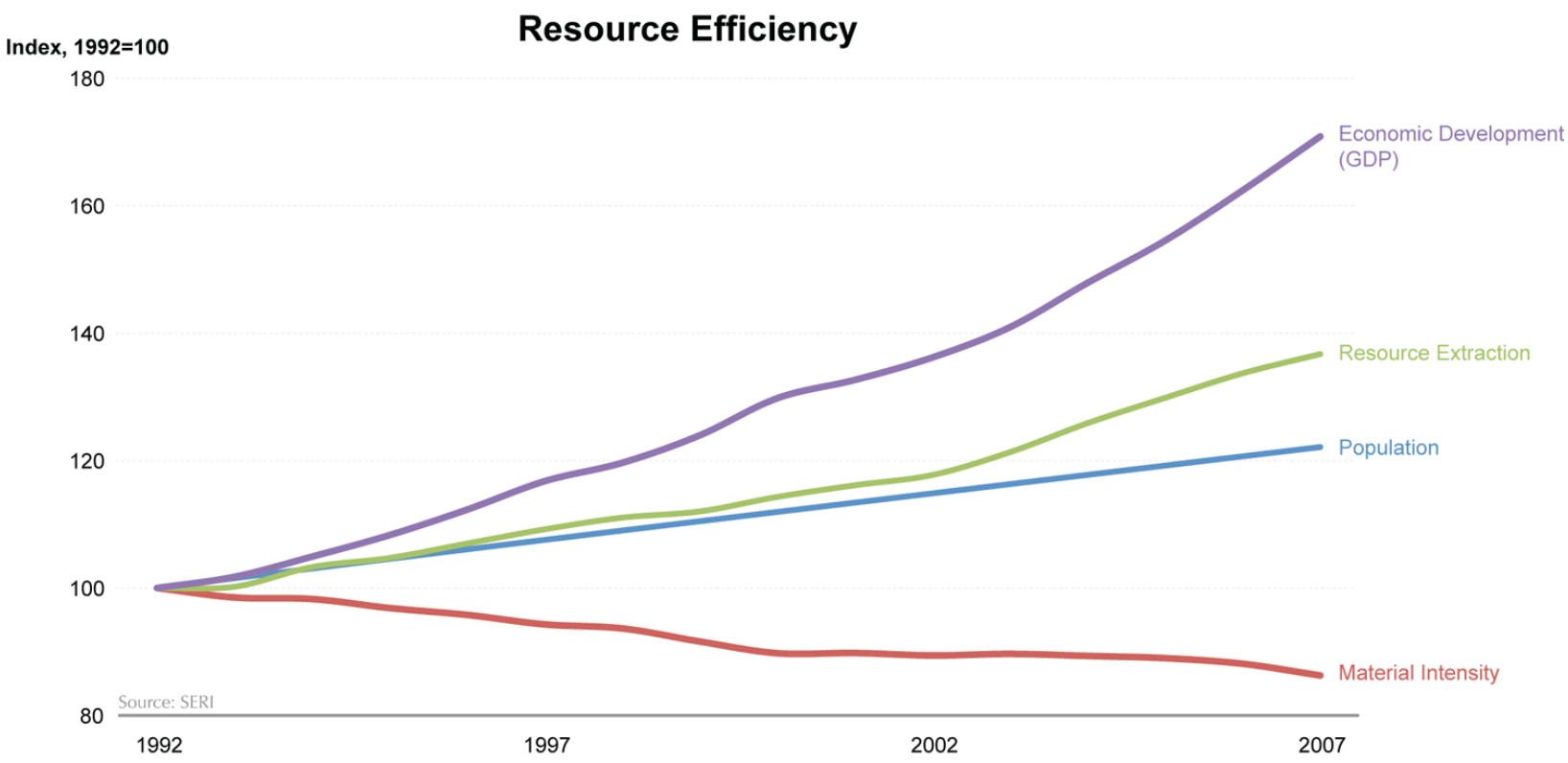

Fig4. More energy and natural resources are being consumed, but the amounts needed per product are declining.

Source: SERI cited in UNEP, 2012

\subsection{Environmental Degradation and Ecological Breakdown}

At the global level, studies on environmental degradation have been undertaken since the 1970s mainly by OCED $(1975,1989)$. The World Bank 1991 and some research institutes and universities (Hussein, 2007). In countries of South Asia notably Pakistan a recent World Bank report demonstrates that environmental degradation is threatening to undermine Pakistan growth prospects. A world Bank study reveals that the degradation of Pakistani resource base and high burden of disease is costing Pakistan at least 6 percent of GDP or about Rs. 365 billion (US\$ 6 billion) annually(World Bank ,2007).

The Latin America and the Caribbean policy brief reports that key findings of the Millennium Ecosystem Assessment, finalized in 2005 reveals that; 
$60 \%$ of world ecosystem services have been degraded. Among the 24 evaluated ecosystems, 15 are being damaged, about quarter of the Earth's land surface is presently cultivated. People now use between $40 \%$ and $50 \%$ of all available freshwater running off the land. Water withdrawals have doubled over the past 40 years. Over a quarter of all fish stocks are overharvested. Since 1980, about 35 percent of mangroves have been lost. Nutrient pollution has led to eutrophication of waters and coastal dead zones Species extinction rates are now 100-1,000 times above the background rate (LAC Policy Brief, 2009).

Sachs (2015) argued that in the 22 years since the world signed the UN Framework Convention on Climate Change at the Rio Earth Summit, there has been far too little progress toward real action.

There have been water and air pollution which endangers the health of urban residents,

causes chronic illnesses, and kills millions (Hinrichsen,et al;2002). Nuclear proliferation, Western multinational corporations and oil resource extraction have principally resulted to environmental degradation. Recent UNEP data (2012) shows a disproportionate percentage of technological induced environmental degradation. Environmental concern has increasingly grown in the era of sustainability. Korten (1995) contends that poverty has been on the increase globally with massive, unemployment, violent crimes, failing families, and environmental degradation.

There are divergent dimensions of global environmental security threats in the era of sustainable development. This suggests that environmental security has been central to the key 21 st century challenges(Ulman,1983;Mathews,1989). Much of this include persistent environmental threats such as climate change vulnerability, green house effects, ozone layer depletion, tsunamis, earthquake, cyclones, massive sea level rise and flooding etc. Other life threating environmental disasters such as acid rains, gas flaring in the poor societies of the global south such as the Niger Delta in Nigeria are on the increase. There are other dimensions of security threats such as the resurgence of terrorist groups like Al- Qaeda, ISIS, al-Shabaab etc as explicated.

Korten (1995) notes that although economic output has experienced a fivefold increase since 1950, the ecosystem cannot sustain its present growth. Ohmae (1995) calls this the "resource Illusion" and contends that, countries are actually slowing their own growth and that growth must take account of environmental factors to be meaningful.

The cosmetic internationalization of sustainability is further demonstrated with genetically mutilated crops, creolization, which has health implications such as cancer. Harvey,(2005) confronts the understanding of transnational capitalism as a progressive force spearheading the global expansion of democracy. He argues that his results in the retreat of the state and conflation of capitalism with democracy.

Sustainability is thus professed as an important element of transnational corporate multiculturalism with less cogitation on transformation of human and non -human species.

Table1. Per capita energy consumption of selected countries

\begin{tabular}{|c|c|c|c|c|c|c|}
\hline \multicolumn{3}{|c|}{ Energy (Kilograms of oil equivalent) } & \multirow{2}{*}{\begin{tabular}{|l|} 
GNP \\
rank \\
1998 \\
\end{tabular}} & \multirow{2}{*}{$\begin{array}{l}\text { GNP per } \\
\text { Capita rank } \\
1998 \\
\end{array}$} & \multirow{2}{*}{$\begin{array}{l}\text { Population } \\
\text { (millions) } \\
1998\end{array}$} & \multirow{2}{*}{$\begin{array}{l}\text { No. of citizens compared to } \\
\text { U.S. citizens } \\
1997 \\
\end{array}$} \\
\hline Country & 1980 & 1997 & & & & \\
\hline United States & 7,973 & 8,076 & 1 & 10 & 270 & 1 \\
\hline Germany & 4,603 & 4,231 & 3 & 13 & 82 & 2 \\
\hline Japan & 2,967 & 4,084 & 2 & 7 & 126 & 2 \\
\hline Russian Federation & 5,414 & 4,019 & 16 & 97 & 174 & 2 \\
\hline China & 610 & 907 & 7 & 145 & 1,239 & 9 \\
\hline Nigeria & 743 & 753 & 55 & 181 & 121 & 11 \\
\hline Indonesia & 402 & 693 & 30 & 149 & 204 & 12 \\
\hline India & 352 & 479 & 11 & 161 & 980 & 17 \\
\hline Bangladesh & 172 & 197 & 53 & 173 & 126 & \\
\hline
\end{tabular}

Source: World Development Report 2000, World Bank.

\section{Conclusion}

The sustainability model as could be seen has been appropriated by various stakeholders to mean practically different things. But it is important to reposition all stakeholders particularly from the industrialized North to respond to its core ideals including new modes of behavior and lifestyles that 
may not have sustainable utility. Sustainability becomes superficial and less internalized as the distinctive features of deleterious resource use and lifestyles of the West suggest.

The objective of this paper is to find answers to some of the critical issues raised on sustainable development as a paradigm riddled with contradictions. This study revealed the involvement of a number of actors and stakeholders, notably the industrialized affluent societies, the multi-national companies and core capitalist interests. It also demonstrated that the poor societies also contribute to global environmental degradation such as pollution and deforestation but not as much as the industrialized societies.

This research has demonstrated that a non-grounded use of sustainability is antithetical to inclusive and participatory development. The research has shown that development could be sustainable- only if it could meet the long term needs of the wider human and non-human species in particular, the poor and marginalized segments of the society. This underscores the need for novel policy framings on sustainable development as evidence of poor commitment to the sustainability ideals abound (Hobson, 2003; Schor, 2005).

Ironically, developmentalism has been largely a Western construct and this has increasingly been part of the major failure of the sustainability paradigm. Western institutions such as the IMF and the World Bank spearhead contemporary development agenda which often pay lip service to core issues of development especially in the periphery societies.

There is need to deliver the legitimate claims of sustainable development, achieving such development feat will require collaborative actions to strengthen environmental, social and economic strands of sustainable development.

To achieve sustainable development beyond 2015requires a new attitude and rethinking. Recent changes suggest that the climate change vulnerability threatens human and non- human species. Divergent environmental disasters such as the hurricane, tsunamis, earthquakes, cyclones etc escalate as a result of poor commitment to environmentalism.

Promoting collaborative sustainable management of human and non- human species are plausible mitigation measures. Human species are unsustainably used with endeavors such as forced labour, human trafficking, prostitution. Thus, sustainable development is not an exclusive ecological discourse. There are challenges of malnutrition, food insecurity, chronic diseases pervasive in the low income societies which are at variance with sustainable development. The core issues of persistent inequality among the poor and rich societies remains a growing challenge to sustainable development (Pikitee and Emmanuel, 2003; World Bank, 2015; Imoh-Ita and Amadi, 2016).

Similarly, recent debates have interrogated the sustainability import of rapid urbanization in places like Asia, Latin America and Africa. Uneven development should be strategically structured for preservation of the natural environment. The world is yet to recover from the about of global economic recession that hit America in 2008.

Currently the global decline in the oil economy invokes the implicit need to adopt more renewable resource extraction strategy. Sustainable development will be truly sustainable if it could involve a number of elusive issues such as climate change vulnerability, global poverty and inequality, ecological breakdown, gender inequality, racial discrimination and unsustainable consumption these need to be taken seriously.

The resurgent disease economy increasingly threatens sustainable development. Special attention should be given to novel strategies to create new meaning to sustainable development to check growing ambitious of the industrialized societies. There should be collaboration and action-plans to adapt and pursue a new sustainable development agenda. This requires drastic changes in production and consumption patterns of the industrialized societies which taints nature, this will not only intensify resource renewal rather it trickles down to the strengthening of economic governance.

At post Washington consensus and its inability to institutionalized equitable development like most Western policies, Joseph Stiglitz (2003) suggests the need for global economic structures to broaden development focus against sets of narrow objectives to meet development needs of the poor societies. He refutes the reliance on Western experts for development of the poor societies. 
Policy issues raised here include means of financing sustainable development, means of implementation (MOI), environmental justice and accountability by the high income societies which remains contestable.

Unless the affluent societies are made more accountable, responsible and responsive to environmental issues, it is likely that the SDGs will remain elusive.

\section{REFERENCES}

Amadi L. (2014a).Talking Right, Walking Wrong: Global Environmental Negotiations and Unsustainable Environmental Consumption Paper presented at the International Conference on "Negotiation: Dispute Resolution and Conflict Management in a Changing World" April 10-12, 2014 at Kennesaw State University, Kennesaw (Atlanta Suburb), Georgia, USA.

Amadi L and Agena J (2015). Globalization,Culture Mutation and New Identity: Implications for the Igbo Cultural Heritage.African Journal of History and Culture. Vol 7(1)016-027

Amadi L,Igwe P and Wordu S.(2014). Sustainable Development, Greening and Eco-efficiency -A Political Ecology.Journal of Sustainable Development Studies.Volume 7, Number 2, 2014, 161 196

Amadi L,Wordu S and Ogbanga M(2015).Sustainable Development in Crisis? A Post Development Perspective. Journal of Sustainable Development in Africa (Volume 17, No.1, pp 140-163. Clarion University of Pennsylvania, Clarion, Pennsylvania.

Amadi L, Imoh-Ita I and Obomanu E (2016).Culture Mutation in the Era of Globalization: Africa in Perspective. International Journal of History and Cultural Studies (IJHCS)Volume2, Issue 1, 2016, PP 16-32

Bakan, J(2005). The Corporation: The Pathological Pursuit of Profit and Power.Free Press

Bakari, M (2013). "Globalization and Sustainable Development: False Twins?". New Global Studies7 (3): $23-56$

Berman, M (1982) All That Is Solid Melts into Air New York: Penguin Books, pp. 94-95.

Bello W .(2003).“"The Future in the Balance "Accetance Speech for Right Livelihood Award.Swedish Parliament, Stockholm (December 8), Available at www.rightlivelihood.se/speeches/bello.htm (accessed on Februray 23, 2015).

Birdsall N (2005). Rising Inequality in the New Global EconomyWorld Institute for Development Economics ResearchAnnual Lecture No2.

Callinicos, A. (2009). Imperialism and Global Political Economy. Polity Press.

Caprotti, F. (2014) .'Critical research on eco-cities? A walk through the Sino-Singapore Tianjin EcoCity'. Cities 36: 10-36.

Chadha, K., \& Kavoori, A. (2000). Media imperialism revisited: Some findings from the Asian case. Media, Culture and Society, 22, 415-432.

Chomsky N "The Croatian Feral” Tribune, April 27, 2002

Collier, P.(2010).The Plundered Planet Why We Must--and How We Can--Manage Nature for Global Prosperity .Oxford University Press

Clemens M and Moss T.(2005).What's Wrong with the Millennium Development Goals?Centre for Global Developmentpp1-6.

Daily G and Ehrlrich P(1996).Socioeconomic Equity ,Sustainability and Earth's carrying Capacity Ecological Application,Vol.6,No.4,991-1001

Dasgupta, P (1993).An inquiry into well-being and destitution.Oxford University press Oxford,England

Davidson, D.\&Hatt. K, etal.(2005) Consuming Sustainability Critical Social Analysis of Ecological Change.Fernwood publishing Clare Avenue Winnipeg Maritoba

Dodds F ,etal. (2012). Only One Earth.The long Road via Rio to Sustainable Development, Routledge Taylor and Francis Group, London

Dressen P.(2003).Eco-Imperialism: Green Power, Black Death.Free Enterprise Press: Belleview, WA.

Easterly W.(2009).How the Millennium Development Goals Are Unfair to Africa. World Development, Vol. 37, No. 1 
Escober A (1995) Encountering Development.The Making and Unmaking of the Third World.Princeton,Princeton University Press

Gasper D. (2004).The Ethics of Development: From Economism to Human DevelopmentEdinburgh University Press, 2004 - pp- 255

Gareau,B "We Have Never Been 'Human': Ontological and Methodological Arguments for and against Science Studies and Its Linking to Marxist Political Economy," paper presented in Section on Marxist Sociology Session, "Marxism and the Environment," Annual Meetings of the American Sociological Association, San Francisco, 2004

Goodland R(1995).The Concept of Environmental Sustainability Annual Review of Ecological and Systematics, Volume 26pp1-24.

Harvey, D (2005).Brief History of Neoliberalism; New York: Oxford University Press .

Hawken P, Lovins A, Lovins LH. (1999). Natural capitalism: creating the next industrial revolution. Boston (USA): Little, Brown and Company

Hinrichsen, D., Salem,R., and Blackburn, R.(2002). Meeting the Urban Challenge. Population Reports, Series M,No.16. Baltimore, the Johns Hopkins Bloomberg School of Public Health, Population Information Program.

Hobson,K (2003).Consuming Environmental Sustainability and Human Geography in Australia:A missing Research Agenda?Australian Geographical Studies.41(2)148-155.

Holdren J, Daily,G and Ehrlich P(1995).The meaning of sustainability:biogeophysical aspects.P317in:M Munasinghe and $\mathrm{W}$ Shearer,eds,defining and measuring sustainability: the bio geophysical foundations. World Bank, Washington,DC.,USA

Hove H (2004).Critiquing Sustainable Development: A Meaningful Way of Mediating the Development Impasse?Undercurrent Volume I, No 1.48-54

Institute for Economics \& Peace(2015) Global Terrorism Index Report. pp 90-92 accessed 3/6/ 2016.

Jacob M (1994).Toward a Methodological Critique of Sustainable Development

The Journal of Developing Areas Vol. 28, No. 2 (Jan., 1994), pp. 237-252 Page Count: 16

Kibert. C, Thiele. L, Peterson.A and Monroe .M, ( 2012) .The Ethics of Sustainability .http :// scholar .google. com/scholar? q=related: tYgJRAQtgv

Korten D(1995).When Corporations Rule the WorldKumarian Press Inc./Berrett-Koehler.

Kovel,J (2000). "The Struggle for Use Value," Capitalism Nature Socialism, 11, 2, pp. 3-23

Kraidy,M (2002) .Hybridity in Cultural Globalization Communication Theory, 12 (3), 316-339

Lamberton G (2005).Sustainability accounting-a brief history and conceptual frame work Accounting Forum. Volume 29, Issue 1, Pages 7-26.

Lye Liang F (2010). Towards a Liveable and Sustainable Urban Environment: Eco-cities in Asia. Singapore: World Scientific.

Nederveen Pieterse J (2010).Development Theory: Deconstructions / Reconstructions. London: SagePublications Ltd. 2nd Edition.

Chossudovsky M (2015).The Globalization of War, America's “Long War" against HumanityGlobal Research Publishers.

Pierre-Louis K "Hacking into the Green Economy" Urban Times online magazine, 12th Feb, 2012 Available at: http://urbantimes.co/2012/02/green-economy. Retrieved 15/11/2012

Rosenau. J ,(1997). Complexities and Contradictions of Globalization. Current History Vol.96 No 613.

Schuftan C(2003) The Emerging Sustainable Development Paradigm:A Global Forum ON The Cutting Edge of Progressive Thinking. The Fletcher Journal of International development VOLUME XVIII - pp 7-78.

Sachs, W.(1992).The Development Dictionary: A guide to knowledge as power. London: Zed Books

Sachs J "The Year of Sustainable Development"Available at http://www.project syndicate .org/commentary/sustainable-development-2015-by-jeffrey-d-sachs-2014 12\#rtsdqy GZ4JQ b81sO.99 
Schor, J.(2005).Prices and quantities: Unsustainable consumption and the global economy, Ecological Economics 55 (2005) 309-320

ShivaV (2002), Water Wars: Privatization, Pollution, and Profit,. Between The Lines Press, Toronto. pp156

Stern, P, Toward a Working Definition of Consumption for Environmental Research and Policy In;Paul C. SternDietz,T , Ruttan V, Socolow,R and Sweeney,L Eds; (1997)Environmentally Significant Consumption:Research Directions Committee on the Human Dimensions of Global Change, National Research Council. National Academies Press

Terpstra, V and David, K (1991). Cultural Environment of International Business, Cincinnati, OH; South-Western College Publishing.

Tomlinson.J.(2003). Globalization and cultural identity. Retrieved Jan 11, 2015, from http:// www. polity.co.uk/ global/pdf/GTReader2eTomlinson.pdf

UNEP (2011) Towards a Green Economy" United Nations Environment Program. Oxford Press

Vogel R.(2009)Combating Globalization: Confronting the Impact of Neoliberal Free Trade Policies on Labor and the Environment. Available at http://combatingglobalization.com

Wackernagel, M, et al., (1999). National natural capital accounting with the ecological footprint concept. Ecological Economics 29 (3), 375-390.

Weinstein B(2008). Developing Inequality. The American Historical Review 113 (1): 1-18.

Wernick, I, (1997). Consuming materials: the American way. In: Stern, Paul, et al., (Eds.), Environmentally Significant

Westein,B (2008) Developing Inequality The American Historical Review 113 (1): 1-18.

WHO(2002)WHO/UNICEF Joint Monitoring Programme for Water Supply and SANITATION. Global water supply and sanitation assessment 2000 report. Geneva, World Health Organization (WHO) and United Nations Children's Fund (UNICEF), Apr. 24, 2001. 79 p. (Available: <http://www.who.int/water_s a n i t a t i o n_ h e a $1 \mathrm{th} /$ Globassessment/Glasspdf TOC.

Worldword Institute (2011) State of the World 2011: Innovations that Nourish the Planet Available at http://www.worldwatch.org/sow11

WCED, (1987). Our Common Future.Oxford University Press,New York,USA

UNCED,(1992). Agenda 21: Rio Declaration, Oxford Press

WSSD,(2002). Johannesburg Plan of Implementation, Oxford University Press

Soros, G., (2008). 'America must lead a rescue of emerging economies', Financial Times, 29

October, p. 11. 